\title{
HACIA UNA CONCEPCIÓN DEL JUICIO DEMOCRÁTICO LATO SENSU Y DEL JUZGADOR DEMOCRÁTICO EN MÉXICO DESDE LA TEORÍA DEL COTO VEDADO
}

\section{TOWARDS A DEMOCRATIC CONCEPTION OF DEMOCRATIC JUDGMENT LATO SENSU AND THE DEMOCRATIC JUDGE IN MEXICO FROM THE THEORY OF THE PROHIBITED LIMITS}

Joaquin Ordoñez ${ }^{1}$

\begin{abstract}
Resumen
Se esbozan algunas condiciones teóricas necesarias para conceptualizar el juicio democrático lato sensu a partir de determinados conceptos de la teoría del coto vedado, con la finalidad de indagar en las características y requisitos para poder calificar de democrático a un proceso jurisdiccional. Se parte de la idea de que los juicios democráticos deben realizarse no solamente en los órganos jurisdiccionales electorales, esa sería una idea restringida (o stricto sensu), sino que deben operar en toda actividad jurisdiccional, de ahí su sentido amplio (lato sensu). Se plantea la necesidad de que en toda actividad jurisdiccional influyan aspectos democráticos si se quiere lograr el objetivo social de una eficaz y eficiente impartición de justicia, para lo cual se consideran algunas categorías de la teoría del coto vedado. Finalmente, para que el juicio democrático lato sensu pueda aplicarse en la realidad se requiere que el juzgador sea democrático cuyas cualidades y características también se bosquejan desde la referida teoría.
\end{abstract}

Palabras clave: Juicio Democrático; Coto Vedado; Juzgador Democrático; Teoría Democrática.

\begin{abstract}
It outlines some theoretical conditions necessary to conceptualize the democratic judgment lato sensu from certain concepts of the prohibited limits theory, in order to investigate the characteristics and requirements to be able to qualify as democratic a judicial process. It is based on the idea that democratic judgments should be carried out not only in electoral jurisdictions, but rather that it should be a restricted idea (or stricto sensu), but must operate in all jurisdictional activities, hence its large sense (lato sensu). It is proposed that in all jurisdictional activities democratic aspects should be influenced if the social objective of an effective and efficient administration of justice is to be achieved, for which some categories of the prohibited limits theory are considered. Finally, for the democratic judgment lato sensu can be applied in reality requires that the judge is democratic whose qualities and characteristics are also outlined from the said theory.
\end{abstract}

Keywords: Democratic Judgment; Prohibited Limits; Democratic Judge; Democratic Theory.

\footnotetext{
1 Docto en Derecho. Profesor e investigador de tiempo completo de la Facultad de Derecho de la Universidad Autónoma del Estado de México. E-mail: joaquin.o@me.com
} 


\section{INTRODUCCIÓN}

En México la deficiente impartición de justicia (especialmente la penal y civil), derivada de la incapacidad estatal para proporcionar orden y seguridad (Fuentes, 2017), es un problema que debe atenderse y corregirse con urgencia si se pretende calificar como un verdadero Estado democrático. ${ }^{2}$ Incluso ya algunos autores han hecho referencia a varios de los problemas que presenta la administración de justicia en México (Soberanes, 1993; Ruiz, 2010; Flores, 1960; Buscaglia, 2006), con lo que se hace necesario abordar el problema desde una postura en la que los aspectos democráticos se tomen en consideración; en efecto, la impartición de justicia es uno de los aspectos democráticos de los estados en la actualidad, pues del objetivo es que todos los ciudadanos (y todas las personas) puedan gozar de los derechos que tienen establecidos constitucional y legalmente, para lo cual es necesario que la estructura gubernamental lleve a cabo sus funciones de acuerdo con las reglas establecidas para que la democrática actividad de impartición de justicia sea eficiente pero también eficaz. ${ }^{3}$ Una de las consecuencias de lo anterior es una falta de transparencia, así como determinadas inconsistencias e incoherencias en la interpretación y aplicación de las normas, tanto penales como civiles, que desembocan en fenómenos de abuso en cuanto a la discrecionalidad sustantiva y procesal, lo cual se encuentra estrechamente relacionado con la corrupción judicial que afecta a la ciudadanía (Buscaglia, 1999; Buscaglia y Van Dijk, 2003), y al final es una afectación directa a la gobernabilidad democrática y a la posibilidad de garantizar cabalmente el respeto de los derechos humanos y de los principios que sustentan a un Estado de derecho. En el mismo sentido, la falta de efectividad del sistema de justicia está relacionada, entre otras causas, con frecuentes abusos de discrecionalidad sustantiva, procesal y administrativa, así

\footnotetext{
2 De acuerdo con el Rule of law index 2016, en cuanto a los aspectos civil justice (integrado por los indicadores: accessibility and affordability, no discrimination, no corruption, no improper gov. Influence, no unreasonable delay, effective enforcement, y impartial and effective ADRs) y criminal justice (integrado por los indicadores: effective investigations, timely and effective adjudication, effective correctional system, no discrimination, no corruption, no improper gov. influence, y due process of law), México obtuvo un ranking regional de 26/30 y 27/30 respectivamente, lo que significa que está posicionado como los peores, mientras que en ninguno de esos indicadores alcanzó la mínima de .50 (salvo en impartial and effective ADRs); fuente: World Justice Project, Rule of law index 2016, en línea: http://data.worldjusticeproject.org/\#/index/MEX, consulado el 18 de julio de 2017.

${ }^{3}$ La eficiencia se puede entender como la capacidad de disponer de alguien o de algo para conseguir un efecto determinado, mientras que la eficacia es la capacidad de lograr el efecto que se desea o se espera (Real Academia Española, 2017); en una situación ideal, los principios democráticos que sustentan a un Estado deben operar a través de una determinada estructura, tanto jurídica como social, la cual debe tener la capacidad de disponer de sus diversos elementos (humanos, materiales, legales, procesales, etc.) para lograr el efecto deseado que es el de la impartición de justicia.
} 
como altos niveles de corrupción en los subsistemas de policía y jurisdiccional (Buscaglia y Dakolias, 1995). Por tanto, la cuestión es ¿qué hacer ante tal problemática? ¿qué se debe corregir o qué se debe implementar para que la actividad medular de impartición de justicia en un estado democrático sea coherente con los postulados democráticos? La respuesta a lo anterior se puede encontrar en la cabal conceptualización del juicio democrático lato sensu a partir de algunos de los postulados de la teoría del coto vedado.

Ahora bien, para la lectura de este trabajo se deben distinguir dos tipos de juicios: aquellos cuyo objetivo es resolver controversias derivadas de la específica actividad de organizar elecciones estatales (que se pueden denominar juicio democrático stricto sensu), y aquellos cuya meta jurisdiccional se encuentra en el rango de las demás ramas del Derecho, la que llamaré juicio democrático lato sensu (en adelante JDLS). La premisa es que toda actividad jurisdiccional estatal tiene efecto no solamente en la situación particular de los justiciables que se someten a la jurisdicción del respectivo órgano estatal, sino también en la práctica democrática general, esto es, considerada en su sentido más amplio, en aquel que implica una práctica cotidiana, una forma de vida, y no restringido a solamente los procesos de elección para formar gobiernos. A partir de ese antecedente surge entonces la necesidad de conceptualizar el JDLS, es decir, la actividad estatal de juzgar cuya meta directa no es determinar derechos y obligaciones electorales $\multimap$ democráticos per se-, pero que afectan de forma indirecta a la conformación y a la práctica democrática en un Estado Constitucional. Al respecto, la teoría del Coto Vedado (Garzón, 1989) expresa que en una democracia existen límites en los que se aplican los parámetros democráticos y sus instrumentos y, por tanto, se cumplen sus metas y objetivos. En los JDLS's, el juzgador tiene el deber (también legal, es decir, derivado del mismo Derecho positivo) de apegarse a las reglas de la democracia y también a algunos parámetros de la referida teoría, ya que no debe rebasar los límites de decisión que se encuentran dentro de lo permitido por la propia norma jurídica.

Ahora bien, la importancia de realizar la revisión teórica planteada estriba en la siguiente cuestión: ¿cuáles deben ser los criterios democráticos que fundamenten la actividad jurisdiccional? Con lo anterior se justifica la reflexión sobre cómo debe ser el hombre democrático. En un mundo en el que las normas jurídicas tienen prevalencia en casi todas las actividades del ser humano y en el que la democracia es uno de los sistemas con los que cuenta para un mayor logro de los objetivos estatales y ciudadanos, la importancia se sustenta en la necesidad de precisar el significado del JDLS para poder aplicarlo — exigir su aplicación- 
cuando se trate de resolver problemas o fenómenos sociales ${ }^{4}$ desde los órganos jurisdiccionales, ya que una gran parte de ellos son (o al menos deben ser) atendidos desde la posición del juzgador. ${ }^{5}$ Lo anterior en virtud de que una de las formas en las que se concreta la justicia es a través de algunos de los principios democráticos en un proceso jurisdiccional, como la igualdad.

Una adecuada y cabal concepción de lo que debe ser el JDLS, realizado bajo los estándares de la democracia, podría aportar a la resolución de esos problemas que aquejan a la sociedad; si se conceptualizara adecuadamente, una de las consecuencias de la ciudadanía en su interacción con los órganos estatales sería, por ejemplo, que sus actos y su interrelación con las demás personas sería más justa y habría un efecto en la incidencia de sus actos (y resoluciones, en el caso de os juzgadores) tendiente a la protección de los derechos fundamentales y a dar a cada quien lo que le corresponde.

Ahora bien, ¿de qué manera incide en todo esto la teoría del coto vedado? Para responder lo anterior se debe tener en cuenta que dicha teoría postula, en términos generales, la existencia de algunas áreas o zonas prohibidas en las que las personas y los funcionarios públicos en un sistema estatal democrático no pueden incidir con sus decisiones, lo anterior derivado de las características propias de los aspectos jurídicos, políticos y sociales contenidos en dicha zona, por lo que, el juicio democrático debería postular que esas prohibiciones sean el parámetro por el que los juzgadores se rijan, con el consecuente efecto de abonar al funcionamiento de la democracia al interior de un Estado. En el ámbito de la actividad del juzgador (aquel que no lo es para lo electoral ex profeso) tiene su importancia la premisa anterior, ya que los individuos que acuden a los órganos estatales jurisdiccionales en busca de impartición de justicia, lo hacen con la esperanza (algunos con la seguridad) de que el juzgador lo hará respetando esos ámbitos en los que puede tomar decisiones y restringiéndose en aquellos en los que no debe, con base desde luego, en principios como el de legalidad y otros de corte procesal como los de exhaustividad y congruencia. Con todo ello también los actores sociales y los juzgadores democráticos podrían ser personas más éticas, individuos con un

\footnotetext{
${ }^{4}$ Los problemas sociales es lo que se espera resolver con la implementación de una democracia estatal, esa es la razón principal de esa forma de gobierno, no solamente el mecanismo de elección (en sus diversos sistemas), sino también la resolución (directa o indirecta) de esa problemática, lo cual corresponde a la clasificación que se ha hecho de la democracia en sustantiva y procedimental, siendo la primera el motivo de análisis en el presente artículo.

${ }^{5}$ No necesariamente electoral (lo cual sería una posición restringida, como ya se vio), sino de cualquier otra materia e independientemente del momento procesal en el que sea interpretada o aplicada la norma jurídica respectiva.
} 
mayor sentido moral que dejen de lado los intereses personales, que eviten la parcialidad en la toma de sus decisiones y con una mayor conciencia de las necesidades de las otras personas que integran a la comunidad, con el consecuente efecto de hacer más eficaz y eficiente la impartición de justicia.

\section{LA NECESIDAD DE CONCEPTUALIZAR EL JUICIO DEMOCRÁtICO LATO SENSU DESDE LA TEORÍA DEL COTO VEDADO.}

Los conceptos son necesarios para la comprensión de la realidad circundante, de ahí surge la necesidad de conceptualizar el mundo y la realidad en la que vivimos y tanto la democracia como las resoluciones de los conflictos que se llevan a cabo bajo esos estándares, no son la excepción, por tanto, ameritan una conceptualización con la finalidad de que la interacción de las personas se vea afectada de forma positiva y la actividad del juez se vea democratizada. Asimismo, los conceptos también son necesarios para re-orientar la actividad del hombre en sociedad, ya que la ideología prevaleciente en la mente de las personas es la que determina sus acciones; en efecto, dependiendo de la idea que se tenga acerca del juicio democrático se puede tener, en mayor o menor medida, una participación congruente en un Estado democrático. Es así de importante y necesario conceptualizarlo. No solamente se trata del juicio — como actividad jurisdiccional - que tiene su fundamento en una serie de reglas jurídicas y procesales, sino que además tiene su basamento en las reglas esenciales de lo democrático.

Para llevar a cabo esa formulación conceptual es necesario plantear la pregunta ¿Qué es el juicio democrático? ya que de la respuesta que se dé a la misma depende la comprensión que se tenga y que se deba tener respecto a esa actividad y también respecto al impacto que pudiera tener en la sociedad. Por ello, es importante el concepto de democracia, ${ }^{6}$ ya que sin él no podríamos establecer la necesidad de comprender el concepto de juicio democrático; así, en una definición de democracia se hace alusión al poder del pueblo, al poder público de las personas que forman parte del elemento humano del Estado, es decir, el ciudadano, ente que emite determinadas decisiones de carácter público por sus cualidades otorgadas en la norma fundamental y en las leyes. Este concepto obliga a pensar en la democracia como cantidad,

\footnotetext{
${ }^{6}$ La teoría de la democracia ha desarrollado un sinnúmero de definiciones, desde aquella que la considera desde su etimología, es decir demos pueblo y kratos poder, hasta las modernas concepciones que incluyen conceptualmente muchos elementos relacionados con lo social y lo político sin mencionar otros aspectos de la vida en sociedad.
} 
como masa, como fuerza numérica que al manifestarse puede formular una decisión. De hecho, este es uno de los aspectos que sustentan al principio democrático de mayoría, pero no es el único, ya que como adjetivo también hace referencia a las cualidades que debe tener un ente o un acto y que deben ser coincidentes con las suyas, es decir, aquellos principios que la fundamentan, como libertad e igualdad, de tal manera que se puede hablar de educación democrática, de economía democrática, etc., como una característica deseable en esas áreas que las harían más justas y, de paso, más acordes con un sistema político, social y jurídico de un Estado cuya norma fundamental lo erige como democrático. Sin embargo, puede haber un sesgo $^{7}$ en la conceptualización de democracia que podría llevar a otorgarle dicha cualidad a determinada situación de la vida social en razón de afirmar que la mayoría de la población (o muchos pobladores) deben tener acceso a ello, como un sinónimo de masificación ${ }^{8}$ (desde luego, infundada), en la que todos o muchos —o la mayoría — tienen el derecho de acceder, de pertenecer, de disfrutar, de ejercer, etc., aquello que está calificado de democrático; según esta variante conceptual, cualquiera puede acceder y un ejemplo de lo anterior es la creencia de que la educación ${ }^{9}$ democrática significa solamente (o al menos preponderantemente) que todos tienen el derecho de recibirla. Esa postura representa un riesgo, ya que, si quisiéramos trasladarla al tema de la actividad jurisdiccional, podría conducir a un razonamiento en el que se

\footnotetext{
${ }^{7}$ El sesgo mencionado puede tener sus raíces en la perspectiva más común que se tiene acerca de lo democrático, la cual lo considera también como un adjetivo sobre alguna actividad, apoyado en la idea de que las decisiones se toman por virtud de la regla denominada mayoría; la causa de lo anterior surge por la práctica cotidiana de ese aspecto de la democracia en las elecciones estatales para conformar órganos públicos de carácter popular y donde la población — transformada en ciudadanía- emite un voto como una forma de expresar su decisión acerca de quién debe ser la persona que ocupe el cargo público en cuestión, y basado en una regla aritmética de la mayoría (que puede ser absoluta o relativa) se determina al postulante ganador.

${ }^{8}$ Al respecto, la doctrina ha considerado que ...los grados de participación ciudadana, de enculturización (sic), de estratificación social, etc., permitirán distinguir y enfrentar diversos tipos o concreciones históricas de este modelo social. Una sociedad de masas no es en principio ni democrática ni autoritaria; puede estar más o menos masificada... (Núñez, 1984); en contraste con lo anterior, el mismo autor en otro artículo expresó: La cuestión, por tanto, estriba en verificar si conceptualmente el término masas lleva aparejado necesariamente los contenidos que aparecen unidos al término masificación, puesto que no cabe duda de que la democracia moderna ha de ser, en algún sentido de la ambigua palabra, una democracia de masas... (Núñez, 1978).

9 Por ejemplo, el artículo tercero de la Constitución Política de los Estados Unidos Mexicanos, en el primer enunciado de su primer párrafo establece textualmente: Toda persona tiene derecho a recibir educación, lo cual, bajo una interpretación gramatical, se entiende como que el único requisito es ser persona para poder recibir educación. Lo anterior tal vez tenga su explicación en la tradición democrática que impregnó la ideología del constituyente y por esa idea de que lo democrático significa todos —o muchos, o la mayoría- o tal vez por el carácter protector que se le dio a la Constitución Política como documento fundamental del Estado mexicano.
} 
postule que un juicio democrático lo es porque la resolución o la sentencia debe ser otorgada por virtud de una circunstancia aritmética: la mayoría.

Sin embargo, el concepto de juicio democrático no debe ser considerado en el sentido de que un conflicto ha de solucionarse haciendo uso de ese instrumento numérico, ya que una solución producida bajo ese procedimiento no implica necesariamente la existencia de justicia en el veredicto final: muchos no es sinónimo de justicia y que un gran número tomen una decisión en determinado sentido no lo convierte en un dictamen justo, no es un juicio de las masas como producto de un proceso matemático para determinar de forma cuantitativa la solución al conflicto planteado (Ordóñez, 2016). El juicio democrático debe ser considerado como aquella actividad fundada en los principios de la democracia y no como aquella ejecutada por la decisión de la mayoría (de las masas o del pueblo) ni como un acto fundado en el supuesto derecho de todos $\multimap$ de la mayoría — de acceder a la emisión de decisiones de carácter jurisdiccional. Lo anterior significa que para poder transitar hacia una concepción del juicio democrático se debe tener en cuenta no solamente esa conceptualización de 10 democrático que goza de una mayor notoriedad, sino también otras vertientes: las que consideran a la democracia como un sistema de vida. ${ }^{10}$

Ahora bien, la concepción del poder público —en sus múltiples variantes políticasimplica una peligrosidad latente respecto a quién lo detenta, por ello debe limitarse. Pero también el poder es necesario, ya que proporciona orden y cumplimiento de las normas jurídicas y sociales establecidas, por lo que ese coto también sirve para determinar el campo de acción: lo que sí se puede hacer y lo que no. Tanto una como la otra son necesarios para tener presente a cabalidad el momento en el que se permite o no realizar una acción (como la de juzgar para dirimir alguna controversia, no exclusivamente electoral, sometida al conocimiento de algún órgano jurisdiccional, es decir, los JDLS's). En democracia se trata de una regla de la mayoría que se encuentra limitada y tiene ciertas áreas prohibidas. Las normas jurídicas son el parámetro desde el cual se pueden establecer los límites a la actuación de las personas — sean detentadores del poder público o no-ya que se trata de reglas de control; en democracia, esas reglas establecen, entre otras, que las decisiones de la mayoría son las que deben aplicarse y respetarse, pero el coto vedado se aplica en el momento en el que las decisiones de esa mayoría no deben violentar los derechos de las minorías. En efecto, la validez de la vinculación

${ }^{10}$ En México, también el mencionado artículo tercero de su Constitución Política hace referencia a que el criterio que orientará a la educación, entre otros, será el democrático ...considerando a la democracia no solamente como una estructura jurídica y un régimen político, sino como un sistema de vida fundado en el constante mejoramiento económico, social y cultural del pueblo. 
conceptual entre democracia representativa y coto vedado es bajo la premisa de que aquella no significa el dominio de la mayoría sino la vigencia del principio de la mayoría, basado en la homogeneidad social para impulsar la autodeterminación individual (Garzón, 1989). El coto vedado establece límites que constituyen una certidumbre respecto al campo de actuación de las personas y de aplicación de las propias leyes. La certeza de las normas auspicia la incertidumbre inicial de los problemas que se presentan en la actuación general de la sociedad. Es la incertidumbre convertida en certidumbre derivado de la acción de someter a la potestad democrática del Estado las controversias ocurridas entre los hombres. La democracia es certeza jurídica sobrepuesta a la duda de la pertenencia del derecho, del acreedor a la justicia. Garzón Valdés dice que los derechos que se encuentran comprendidos dentro del coto vedado son los que satisfacen $\longrightarrow$ deben satisfacer — los bienes básicos ${ }^{11}$ también llamados necesidades básicas con una doble clasificación: naturales o derivadas ${ }^{12}$ (Garzón, 1989). En tanto que —igue diciendo_- las necesidades básicas naturales son las mismas en todas las sociedades, las derivadas cambian con el tiempo y con lo social y tienen una tendencia a la expansión.

Entre lo básico natural y lo básico derivado que menciona el autor, existe una distancia cualitativa que implica una determinada evolución en las necesidades del hombre, lo que también significa un incremento en cuanto a la satisfacción de las mismas. Antes ya era un logro someter al conocimiento de los jueces, por virtud de un proceso jurídico heteroaplicativo, una controversia, con la esperanza de que sea resuelta, si no con justicia, al menos con cierto grado de decoro legal. Pero los tiempos cambian y las nuevas tendencias en materia de derechos humanos nos obligan a considerar que no es suficiente la satisfacción de esa necesidad básica derivada con una acción tan elemental, sino que ahora se debe incrementar el cuidado para su eficacia y procurar que en los juicios de cualquier índole (JDLS's) se apliquen las reglas mínimas de la democracia, además de las legales establecidas. Un JDLS es una necesidad básica derivada que no debe intentar satisfacerse con solamente lo que de forma superficial se tiene a la mano respecto de la normatividad en materia de juicios, sino que, además, se deben aplicar los nuevos criterios de derechos fundamentales, de derechos humanos, de equidad de género, y en general de protección de las minorías (derivados del neoconstitucionalismo).

Dentro del concepto de coto vedado han de resguardarse los derechos fundamentales no negociables, lo cual constituye una condición necesaria de la democracia representativa y

\footnotetext{
${ }^{11}$ Aquellos que son condición necesaria — dice Garzón— para la realización de cualquier plan de vida.

12 Un ejemplo de necesidad básica natural, según el autor, son los alimentos, la vivienda, el vestido, etc. mientras que una derivada es saber leer y escribir y estar vestido con un mínimo de decencia.
} 
solamente fuera del mismo cabe el disenso, la negociación o la tolerancia (Garzón, 2005). El autor menciona que: Quien pretenda abrir la puerta del coto vedado y transformar derechos fundamentales en objeto de disenso y negociación elimina la posibilidad de que la democracia pueda satisfacer la pauta de corrección moral que de ella se espera. Un JDLS debe gozar de la protección conceptual que se deriva de la aplicación del coto vedado, ya que se trata de un área que no debe ser invadida por la arbitrariedad. Garzón Valdés también expresa la obviedad respecto al establecimiento del coto vedado, lo que sería traducido en fijar límites a la tolerancia y rechazar el relativismo cultural; para ello se requiere de algún criterio que permita distinguir las buenas de las malas razones, es decir, algún criterio de corrección (Garzón, 2000), el cual podría estar constituido por los elementos democráticos esenciales de un juicio, que a su vez son el respeto por la reglas procedimentales y por los mínimos establecidos; lo anterior para que el juicio pueda ser calificado de justo. Dentro de esa esfera se encuentran los principios procesales que son aceptados en la mayoría de los sistemas jurídicos ${ }^{13}$ (que cuentan con dichos instrumentos) para garantizar la impartición de justicia imparcial (y, por tanto, democrática). En una definición de los principios procesales, de acuerdo a la doctrina, se trata de criterios o ideas fundamentales, contenidos de manera explícita o implícita en el ordenamiento jurídico y que refieren a las características principales del Derecho Procesal para orientar el desarrollo de la actividad jurisdiccional (Ovalle, 1994); sin embargo, esa concepción se queda corta, ya que el único objetivo que el autor les atribuye es el de orientar el desarrollo de la actividad jurisdiccional, y solamente orientar es una idea que no satisface la magnitud de la importancia que tienen tales principios dentro del, per se, importante y trascendente proceso jurisdiccional. El objetivo va más allá, se trata de aplicar verdaderas reglas de actuación que determinan la forma en la que se han de ejecutar los diversos actos inherentes al proceso jurisdiccional. Son axiomas que sustentan las formas circunstanciales en el tiempo y en el espacio de la actuación del órgano jurisdiccional, de sus integrantes, de los sujetos involucrados y de las reglas jurídicas sustantivas que son materia del juicio. Su finalidad última: que la justicia que se busca con el sometimiento de determinado caso a un proceso jurisdiccional sea un logro eficaz. Por ello, tales principios procesales comulgan con las categorías deónticas derivadas de los principios

\footnotetext{
${ }^{13}$ Solamente por citar ejemplos, en México se tienen algunos principios procesales establecidos a nivel constitucional: debido proceso, presunción de inocencia, audiencia, inmediación, publicidad, oralidad y escritura, impulso procesal, concentración, igualdad, congruencia, economía procesal, preclusión, contradicción, eficacia y probidad, etc.; en otros países como Estados Unidos de Norteamérica: derecho al asesoramiento legal, fianza y prisión preventiva, acusación formal y jurado indagatorio, peticiones antes del juicio, convenio declaratorio, derecho a juicio; en España: legalidad, contradicción, audiencia, igualdad de armas, dispositivo, etc.
} 
democráticos, pues el objetivo de ambos es la justicia, ya que, como quedó establecido antes, al practicar los principios democráticos se desarrollan virtudes cívicas, se respetan los derechos y se ejercita la justicia. Asimismo, el coto vedado es el contenedor de esos aspectos procesales que el juzgador no debe negociar ni debe dejar que su aplicación se vulnere, con ello se demuestra que la teoría del coto vedado es aplicable a los juicios para que puedan gozar de la característica de democráticos en un sentido amplio.

\section{UN ARGUMENTO Y UNA JUSTIFICACIÓN PARA EL JUICIO DEMOCRÁTICO LATO} SENSU

Las instituciones llevan a cabo sus funciones a través de determinados actos, en ocasiones con el establecimiento de reglas y lineamientos. En México, por ejemplo, se han emitido los llamados Protocolos de actuación para quienes imparten justicia. ${ }^{14}$ En dichos protocolos se encuentran determinadas referencias y manifestaciones relacionadas con la democracia, por ejemplo: se expresa que ... la tortura suele percibirse como un acto de otras épocas, de países muy alejados y con gobiernos antidemocráticos... ("Protocolo de actuación para quienes imparten justicia en asuntos que involucren hechos constitutivos de tortura y malos tratos", 2014). Por su parte, la Corte Interamericana de Derechos Humanos —con respecto a la labor de investigación de crímenes por parte del Estado- establece el deber de investigar diciendo que ...constituye una obligación estatal imperativa... ("Caso del Penal Miguel Castro Castro vs. Perú", 2006) y ésta a su vez permite garantizar el derecho a la verdad que en una sociedad realmente democrática o en donde se sabe a cabalidad el concepto de democracia, es una meta concreta que el aparato estatal debe satisfacer ("Caso de la Masacre de Las Dos Erres vs. Guatemala", 2009). También, ese órgano jurisdiccional internacional ("Caso Gelman vs. Uruguay", 2011) ha manifestado lo siguiente:

... La legitimación democrática de determinados hechos o actos en una sociedad está limitada por las normas y obligaciones internacionales de protección de los derechos humanos reconocidos en tratados como la Convención Americana, de modo que la existencia de un verdadero régimen democrático está determinada por sus características tanto formales como sustanciales, por lo que, particularmente en casos de graves violaciones a las normas del Derecho Internacional de los Derechos, la protección de los derechos humanos constituye un límite

\footnotetext{
${ }^{14}$ Entre los cuales se encuentran: los de asuntos que involucren hechos constitutivos de tortura y malos tratos, la orientación sexual o la identidad de género, personas, comunidades y pueblos indígenas, niñas, niños y adolescentes, la perspectiva de género, el caso de afectación a personas migrantes y sujetas de protección internacional, en casos que involucren derechos de personas con discapacidad, etc.
} 
infranqueable a la regla de mayorías, es decir, a la esfera de lo "susceptible de ser decidido" por parte de las mayorías en instancias democráticas, en las cuales también debe primar un "control de convencionalidad" (...) que es función y tarea de cualquier autoridad pública y no sólo del Poder Judicial...

Lo anterior es importante ya que ese órgano puntualiza lo siguiente:

1. La legitimación democrática. Los integrantes del poder público tienen a su cargo la ejecución de ciertas funciones por mandato legal, las cuales determinan su razón de ser, el motivo de su existencia, y esos actos deben estar limitados — coto vedado— por el Derecho para evitar su extralimitación y su abuso que perjudique los derechos humanos y fundamentales dentro de una sociedad.

2. La existencia de un verdadero régimen democrático. Lo formal y lo sustancial se conjugan como dos características indispensables e insalvables para poder determinar ciertamente democrático a un régimen de gobierno.

3. Los derechos humanos como un coto vedado. El campo de actuación de las mayorías con respecto a su función decisoria no es ilimitado, antes bien, hay barreras infranqueables que están constituidas por la tutela al catálogo de derechos humanos por parte de instancias también llamadas democráticas.

En otro documento ("Protocolo de actuación para quienes imparten justicia en casos que involucren la orientación sexual o la identidad de género", 2014) se manifiesta que el derecho a la igualdad y no discriminación son el principio fundante del régimen democrático. En efecto, con toda razón la igualdad es una categoría de la democracia y es un elemento de la práctica democrática al interior de un Estado. Lo anterior se traduce en la obligación de los juzgadores, es decir, en su actividad de juzgar, (el Protocolo lo constriñe específicamente a los juzgadores que conozcan de casos relacionados con la orientación sexual y la identidad de género) para que al realizar esa actividad estatal lo hagan acatando - como principio fundante democrático- esos dos parámetros de igualdad y no discriminación. Todo ello con la finalidad de que el juicio no específicamente relacionado con la actividad comicial estatal sea democrático, que sea un verdadero JDLS. Sin embargo, una de las objeciones al tema de la igualdad y la no discriminación puede ser el razonamiento — justificado— de que en ocasiones es adecuado y hasta necesario tratar así a algunas personas en determinada situación. Relacionado con esto, en otro documento internacional ("Propuesta de modificación a la Constitución Política de Costa Rica relacionada con la naturalización, solicitada por el gobierno de Costa Rica", 1984) se encuentra que: ...por lo mismo que la igualdad y la no discriminación se 
desprenden de la idea de unidad de dignidad y naturaleza de la persona es preciso concluir que no todo tratamiento jurídico diferente es propiamente discriminatorio, porque no toda distinción de trato puede considerarse ofensiva, por sí misma, de la dignidad humana. La idea de que no todo tratamiento jurídico diferente es propiamente discriminatorio, es, de hecho, la razón de ser de la actividad jurisdiccional: dar un tratamiento desigual —pero legal-a quien ha cometido alguna infracción y que ha vulnerado lo establecido legalmente. El requisito: respetar y acatar todos los principios procesales jurisdiccionales y los que comprende también la teoría de la democracia, para que se pueda calificar de JDLS. También, en otro documento internacional ("Relating to certain aspects of the laws on the use of languages in education in Belgium", 1968) se ha establecido que no todas las distinciones de trato son discriminación, al mencionar:

One of the first judgements at the international level determining the scope of the principle of non-discrimination was handed down by the European Court in the decision on the Belgian Linguistic case. In this judgement, the European Court agreed that not all types of differential treatment in the provision of rights and freedoms constitute prohibited discrimination under the Convention. In this judgement, the Court set forth its analytical scheme for determining when prohibited discrimination has occurred: a. the facts disclose a differential treatment; b. the distinction does not have an aim, that is, it has no objective and reasonable justification having regard to the aim and effects of the measure under consideration; and $c$. there is no reasonable proportionality between the means employed and the aim sought to be realised.

Se establecen parámetros que se deben seguir para desarrollar la actividad de juzgar y el esquema para el caso de la discriminación para el caso de tener que juzgar algún caso de discriminación. Los parámetros establecidos hacen referencia a que el individuo que juzgue la discriminación no debe hacerlo por la simple ocurrencia de hechos que verifiquen conductas contenidas en un universo generalizado de tratamientos diferentes sobre las personas y que signifiquen la disminución de algunas de sus libertades o derechos, sino que el juzgador ha de considerar que, además de la evidencia de un tratamiento diferenciado, no existe una justificación para el uso desmedido de los medios empleados y también que falta una proporcionalidad razonable entre los medios empleados para hacerlo. En otro ("Protocolo iberoamericano de actuación judicial para mejorar el acceso a la justicia de personas con discapacidad, migrantes, niñas, niños, adolescentes, comunidades y pueblos indígenas", 2014), se manifiesta que:

Una relación democrática entre los jueces y las Cortes de Estados soberanos, implica el reconocimiento de la creciente influencia del 
derecho internacional, particularmente el Derecho Internacional de los Derechos Humanos, en el derecho interno y el necesario diálogo entre ambos. La universalización de los derechos y la transnacionalización de criterios genera un intercambio de resoluciones emitidas en otros países como referencia para la interpretación de derechos en el propio. Cada vez más, las resoluciones de las Cortes de otros países son orientadoras de los argumentos e interpretaciones que se hacen de los marcos internacionales compartidos.

EI JDLS también implica la comunicación que se pueda desarrollar entre los órganos jurisdiccionales, no solamente son importantes los criterios que se generen localmente, sino también los emitidos internacionalmente y ello habla de una relación democrática. La razón puede llegar a ser simple: salvando las particularidades que cada Estado o nación tenga, los principios de democracia —como libertad, igualdad, tolerancia, etc.-son parámetros universales o que deben acatarse de forma universal. Ese rompimiento de barreras temporales y espaciales en la actividad jurisdiccional, bajo los principios mencionados, es lo que logra la concreción de los JDLS's. Asimismo, uno de los objetivos legítimos en una sociedad democrática es la utilidad pública y el interés social, de acuerdo con lo considerado por la Corte Interamericana de Derechos Humanos ("Caso Comunidad indígena Yakye Axa Vs. Paraguay. Fondo reparaciones y costas", 2005), los cuales se concretan como consecuencia de una democratización en la aplicación de las normas jurídicas, es decir, del juicio democrático. Utilidad pública e interés social son dos elementos que evidentemente pueden encontrarse dentro de la connotación semántica de los principios democráticos, y, por ende, deben comprenderse en el ejercicio jurisdiccional.

Ahora bien, el argumento para el JDLS está en torno de las reflexiones teóricas relativas al proceso judicial como una de las manifestaciones del aspecto legal de la democracia. Es la práctica de la ley, su interpretación y aplicación a la resolución de los casos concretos, la que tiene una intervención importante en la democracia de un Estado. En este punto es importante resaltar que cuando un ciudadano acude a los tribunales a solicitar justicia ocurre una transformación derivada del ejercicio democrático de acudir ante esos órganos, el ciudadano se convierte en un impulsor de la democracia y de sus ideales, se vuelve un legitimador del poder público, el hombre se convierte en ciudadano y el ciudadano se ciudadaniza aún más. Existe una concreción del alcance del poder público y de la capacidad del ciudadano para solicitar su intervención. Esa puesta en movimiento del Estado por parte del individuo que requiere aclaración respecto al alcance de sus derechos y obligaciones, es una de las manifestaciones palpables de la realización de la democracia por una actuación ciudadano-Estado. El poder y los instrumentos de coacción estatales no sólo se encuentran al alcance del hombre, sino que son 
utilizables realmente. Es la acción del poder público puesta en marcha por el incentivo y la petición de los integrantes de la población. Ocurre una proyección ciudadano-Estado. Es una transmutación donde la parte se convierte en el todo: la acción judicial del ciudadano provocando la actividad estatal con la finalidad de que las reglas sociales, legales y constitucionales — democráticas todas—sean respetadas. Es un elemento mínimo en una masa amorfa de ciudadanos que constituyen el elemento población del Estado, que representa y protege, desde su minimalismo, al interés general. Es la máxima expresión de la descentralización de la actuación política y social: darle el poder a quien cuenta con la razón jurídica.

Cuando el ciudadano inicia una acción judicial y pone en movimiento a los órganos estatales cuya función es la jurisdiccional, el proceso comienza con la incertidumbre acerca de a quién le corresponde el Derecho y el órgano estatal encargado de decir el derecho lleva a cabo un proceso de des-incertidumbre democrática derivada del conflicto sub-judice. Es entonces cuando el interés público se convierte en el objeto principal de la actividad de esos órganos del Estado: revisar su legalidad, su legitimidad, su corrección y congruencia de una sociedad inmersa en un sistema democrático basado en la legalidad de los actos. Otra consecuencia de esto es que nadie, ni el Estado, tiene la exclusividad de la justicia, ya que sin el ciudadano no se podría iniciar con el proceso mencionado y sin el Estado no se podría realizar el proceso mismo. Por virtud de lo establecido en la ley _es decir, por la legalidad- el ciudadano tiene la posibilidad de ejercer el poder público surgido de su libertad convertida en ese poder. Con todo ello, el ciudadano se vuelve un elemento indispensable de las reglas sociales, un vigilante de los derechos y de su cumplimiento, es un protector del orden público y de la democracia. La legalidad es un área en la que la democracia y sus instrumentos estatales, así como sus principios fundamentales, pueden accionar y aplican sus preceptos y lineamientos, y fuera de ellos existe una limitación.

Esa acción procesal de poner en movimiento al órgano jurisdiccional para dirimir una controversia tal vez sea más importante que el clásico instrumento de expresión de la democracia: el sufragio. Por ello, es de suma importancia darles a los ciudadanos la posibilidad real de acudir a los tribunales, pues de lo contrario, si el Estado en cuestión no contara con los órganos o con los instrumentos necesarios, se le estarían violentando sus derechos y como consecuencia se estaría disminuyendo la democracia. Realizando una comparativa acerca de la importancia que pudiera tener la posibilidad de la emisión de un sufragio frente a la posibilidad de recibir justicia por un tribunal, es más importante la posibilidad de recibir justicia que la de 
emitir un sufragio, ya que un voto en millones de ellos difumina el daño democrático que pudiera causar con la abstención en la manifestación de su preferencia política, mientras que un ciudadano al que se le obstaculiza para recibir la adecuada impartición de justicia puede representar, aritméticamente, un mayor impacto dentro del universo de los ciudadanos que solicitan la intervención estatal para resolver sus controversias, lo que hace que sea de mayor importancia y efecto en la sociedad democrática.

Por su parte, la justificación para el JDLS se encuentra en la afirmación de que la democracia — su construcción y sostenimiento—no puede ser posible fuera de la legalidad; es decir, no es factible ni realizable la democracia sin considerar la existencia de cuerpos legales que dicten los derechos y deberes de las personas en un Estado. La democracia debe implicar un Estado cuyo gobierno esté regido por leyes, fundamentales y secundarias. En tal sentido, es factible tomar como parámetro de la democracia no solamente el grado de participación o abstención en los procesos electorales de un Estado, sino que además se puede medir por el grado de posibilidad real que hay en dicho Estado para acceder a los sistemas de justicia establecidos legalmente y la eficiencia y eficacia de los mismos. En una real democracia, cada ciudadano cuenta con el poder de acudir ante los órganos jurisdiccionales a que se le imparta justicia democrática. Tan importante es la existencia de un sistema de justicia al interior de los estados, que se ha considerado que sin tribunales no hay gobierno $y$, por tanto, no hay democracia (Schuck y Baldwin, 2004).

La autonomía e independencia de los jueces parece ser elemento clave en la conformación de un Estado democrático, es decir, la neutralidad con la que el juez se debe conducir en la ejecución de las actividades inherentes a su función, debiendo estar libre de afectaciones previas a su juicio personal — sin pre-juicios—, constituyéndose en una verdadera autoridad de balance entre los poderes en conflicto (particulares, órganos de Estado, partidos políticos, personas morales, etc.); para esto hay que considerar la eficacia de la norma, el grado de cumplimiento de la misma, ya que de nada o de poco sirve una norma jurídica que no se cumple en la realidad social, y la ley escrita, la norma jurídica estatal, creada formalmente, constituye solamente una parte de la impartición de justicia en el modelo de sistema democrático, la otra parte está dada por la conducta de los actores sociales, de los ciudadanos, justiciables, órganos de gobierno, etc., y, por supuesto, la actuación de los jueces para balancear dichas circunstancias litigiosas. Es la relación concreta entre el ciudadano y los órganos de poder públicos, entre la democracia como forma de gobierno $\longrightarrow$ de vida-y el sistema jurídico. Es el principio de legalidad manifestado de forma concreta. Una ciudadanía 
que actúa en función de todo ello, siendo congruente con la democracia y con las leyes que rigen la actuación del Estado democrático en cuestión.

También, la independencia del sector jurisdiccional da la posibilidad de que sus juzgadores puedan dictaminar y resolver los casos que se les presentan, haciendo uso de un acto que tiene relación con lo democrático: decidiendo, escogiendo entre varias opciones el método de interpretación de la ley; se trata del ejercicio de libertad que fundamenta a la democracia y que se permite por virtud de ella, respecto a la hermenéutica utilizada. Tal vez sea donde mayormente se puede percibir algún aspecto democrático de la función jurisdiccional: si en los juicios se tiene la necesidad de realizar un acto de decisión sobre qué o cuál método hermenéutico debe ser aplicado en la resolución de algún caso, entonces la libertad como elemento fundamental de lo democrático debe tener una intervención activa e inevitable; lo otro está relacionado con la necesidad de que ese acto de elección sea realizado también bajo los demás estándares que sustentan a la democracia y no solamente el de libertad, sino también, por ejemplo, el de igualdad. Todo lo anterior conduce a considerar la concepción de un JDLS, por la amplitud de casos y de materias en las que los juicios se desarrollan. Finalmente, la justificación para el JDLS se refuerza con la idea de que los principios procesales ${ }^{15}$ son también manifestaciones democráticas que tienen lugar en los procesos judiciales. Por eso, los elementos democráticos esenciales de un juicio son el respeto por las reglas procedimentales y el acatamiento de los derechos sustantivos mínimos que están establecidos en la propia ley y, con ello, poder tener una mayor proximidad a la justicia en la resolución emitida dentro de un juicio. La justicia entonces, adquiere forma a través de la aplicación de los principios democráticos en un proceso jurisdiccional.

\section{LA IMPORTANCIA DE CONCEPTUALIZAR AL JUZGADOR DEMOCRÁTICO DESDE LA TEORÍA DEL COTO VEDADO}

Tal vez la democracia no sea el sistema perfecto y acabado que se quisiera en una sociedad convulsa que sufre los desplantes de poder de las personas que detentan cargos públicos y que apenas soporta los embates de la ignorancia, la pobreza, la delincuencia, y un largo etcétera, pero si al menos los que ejercen esas actividades estatales poseyeran una cabal conceptualización acerca de lo que es la democracia y, por ende, del JDLS, entonces se podrían construir las bases para una futura colectividad más justa. La democracia bien conceptualizada y

\footnotetext{
15 También quedó establecido que esos principios procesales se incluyen dentro de la protección derivada del coto vedado, por ser una esfera a la que se protege de la arbitrariedad.
} 
bien aplicada es una poderosa herramienta para el cambio hacia esa futura sociedad, en la que se podrían corregir muchos errores a consecuencia de una actuación y conducta del servidor público $\longrightarrow$ de la sociedad — ignorantes del cabal concepto de democracia. En este aspecto, la teoría del coto vedado es un auxiliar en la aplicación de los principios democráticos en la actividad jurisdiccional.

Se debe considerar la premisa de que una sociedad buena es aquella en la que hay un máximo de experiencia compartida no solamente entre sus miembros, sino también entre éstos y los de otras sociedades, y la forma de sociedad que posee en mayor grado esas características es la democracia; dicha concepción remata estableciendo que no es solamente una forma de régimen político sino un modo general de vida en asociación que se puede aplicar a diversos ámbitos o realidades sociales (Dewey, 1998). Por ello, no obstante que un juicio estatal (llevado a cabo por el órgano judicial de un Estado) es esencialmente jurisdiccional, sería erróneo considerarlo solamente como un proceso exclusivamente de ese tipo (una visión como esta sería una perspectiva obtusa respecto a la magnitud de lo que representa), sino que además es un proceso social que produce un impacto en la sociedad; esto nos lleva a preguntar ¿cuáles deben ser, además de los legales establecidos, los criterios que fundamenten a la actividad jurisdiccional? y la respuesta es: el criterio que soporte a la actividad jurisdiccional debe ser el democrático, ya que se trata de un sistema de vida que no puede ser ajeno a la actividad de los órganos jurisdiccionales. Para lo anterior es necesario que las instituciones y los órganos jurisdiccionales actúen bajo los parámetros de la democracia, ${ }^{16}$ pero además (y quizás más importante) que los individuos que los integran y que llevan a cabo esa función jurisdiccional, sean hombres democráticos. Pero, ¿qué o quién es el hombre democrático? es aquél que de forma cabal posee el concepto de democracia en su mente $y$, por ende, lo practica de forma cotidiana, en su actuar, en su conducta y en sus decisiones como actor de la sociedad; es quien cumple con las diferentes dimensiones que le imponen las características y principios de la democracia, no solamente cumple con sus deberes de ciudadano o de integrante de una sociedad que está regida por leyes — como la obligación de pagar impuestos—, sino que además se entera de los acontecimientos de su medio social, de los movimientos del Estado y de sus representantes, es un receptor y un crítico de la información que se le presenta por los medios oficiales y no oficiales, ejerce sus derechos constitucionales y legales, se organiza en micro-sociedades basadas en el derecho fundamental de asociación para solicitar que se

\footnotetext{
${ }^{16}$ Desde el punto de vista de los fundamentos democráticos y no del derecho de acceso o disfrute de todos o de muchos.
} 
respeten sus derechos individuales y colectivos, cumple con sus responsabilidades al ocupar un cargo público de elección o de designación, es cabal pero a la vez crítico al expresar sus ideas, y, sobre todo, es un ente que comparece ante los tribunales a pedir que le sean resueltos sus conflictos de intereses con el objetivo de recibir uno de los mínimos de la democracia: justicia (Ordóñez, 2015). Al practicar los principios democráticos se desarrollan otras virtudes cívicas, se respetan los derechos y se ejercita la justicia. Con la sola aplicación de esos principios se podrían empezar a resolver muchos problemas de la sociedad actual. Respetando la libertad la cadena de sucesos en la realidad social desembocaría en un beneficio para los actores involucrados en la misma. Muchos de los males de la sociedad contemporánea son derivados de conductas arbitrarias (en un modo activo del sujeto que las ejecuta) y apáticas (en el modo pasivo), ambas son esencialmente contrarias a las categorías mentales que conforman los principios democráticos. Para erradicar esos comportamientos es necesario democratizarlos. La antítesis de los problemas sociales producidos por la tiranía, totalitarismo, conformismo, apatía, etc., es la democracia. Por ello, la justicia adquiere diversas formas, y una de ellas es a través de la concreción de la democracia y sus principios.

El hombre democrático es aquel que de forma cabal posee el concepto de democracia en su mente $y$, por ende, lo practica de forma cotidiana, en su actuar, en su conducta y en sus decisiones como actor de la sociedad; es el juez que, en cualquier materia, estando influenciado por las categorías conceptuales de la democracia, adopta una forma de pensar y una ideología que eventualmente vierte en su decisión o resolución en forma de sentencia. Ese ciudadano o juez con el concepto adecuado de democracia en su mente y en sus acciones es más poderoso socialmente, tiene mayor efecto su poder social; en un entorno en el que urgen las actitudes democráticas, el hombre democrático sería una solución factible a muchos de los problemas sociales. La democracia no solamente es una serie de postulados axiológicos y filosóficos, analizados de manera abstracta, sino que también representa una praxis cotidiana de la sociedad, una conducta de los hombres y una forma de hacer las cosas y de actuar de los ciudadanos, de fungir y de ejecutar los mandatos legales de los gobernantes. Las elucubraciones sobre democracia no deben quedar en el universo cognoscitivo teórico ya que no únicamente es una cuestión de ciencia democrática abstracta, sino de práctica concreta en la vida cotidiana.

Pero el hombre democrático no lo es todo en una sociedad, también son indispensables las instituciones democráticas representadas en los órganos que ejercen determinadas funciones de gobierno, como los llamados poderes del Estado. La división de poderes está diseñada para lograr el equilibrio gubernamental, específicamente la gobernabilidad como 
punto neutral entre el ejercicio del poder público y el carácter democrático de las decisiones del pueblo y sus representantes (Ordóñez y De Paz, 2017), en donde el ejecutivo y el legislativo ejercen funciones que se complementan pero que también se contraponen generando control institucional. Lo anterior es una más de las manifestaciones de la democracia. El poder judicial no es ni debe ser la excepción: también el aspecto democrático se materializa a través de la configuración de un poder encargado de ejercer la función de hacer respetar la ley; de ahí surge la importancia para el equilibrio de poderes (y para la democracia), el hecho de que el poder judicial sea independiente, aunque no tiene estrictamente funciones contrapuestas ni complementarias con los otros dos poderes, sí es un órgano cuya actividad es democráticamente relevante, ya que evita que el ejercicio del poder (de los detentadores de los otros dos poderes) se vulnere y se vea rebasado, con la consecuente corrupción del mismo. Su función representa al concepto de límite. ${ }^{17}$ La protección del Derecho y el respeto de la ley constituyen el área de protección del judicial, así como la soberanía y la regulación fundamental de ésta en el documento constitucional. En la esencia de lo democrático reside la necesidad de que no se abuse del poder, de que haya límites, ya que existe la tendencia de abuso por parte de aquellos que lo detentan y también por los que gozan de una porción de él; dice Montesquieu que no hay poder que no incite al abuso ${ }^{18}$ o a la extralimitación (Montesquieu, 2013). En suma, la legalidad, como uno de los objetivos de la función del Poder Judicial, es una de las aristas o principio de la democracia que se concreta, entre otros, a través del JDLS.

Ahora bien, uno de los efectos que en materia de democracia deben tener las sentencias es en cuanto a las políticas públicas, aunque hay quienes no comulgan con esta idea bajo el argumento de la dificultad creciente que tienen esos funcionarios para que esto se concrete y para que, al final, se materialice la democracia como forma de gobierno: Los jueces son preparados como abogados versados, usualmente como litigantes y no como especialistas en materia de políticas públicas. Es poco probable que obtengan (o que sepan sacar provecho) del suficiente nivel de información que requiere el análisis adecuado de políticas públicas... (Schuck y Baldwin, 2004). En efecto, los jueces son funcionarios cuyo perfil profesional se encuentra específicamente en el área del Derecho, sin que tenga conocimientos más profundos

\footnotetext{
${ }^{17}$ Funciona para hacer respetar ese coto vedado, para no vulnerar la prohibición del acceso a ciertas áreas de acción no permitidas en el desarrollo de la función de los detentadores del poder. Lo anterior se cumple al momento en el que el poder judicial mantiene dentro del área de la legalidad a los otros poderes $y$, en general, todo lo que sea sometido a su conocimiento para resolución.

${ }^{18} \mathrm{Y}$ establece que para no abusar del poder es necesario que la naturaleza misma de las cosas le ponga límites.
} 
o especializados en administración pública o en politología (a menos que posea estudios profesionales en esa materia, lo cual no es requisito para que pueda fungir cono juzgador), sin embargo, su actividad impacta en las políticas públicas a través de los criterios que se generan con la resolución de los casos sometidos a su conocimiento y que son vertidos en el texto de sus sentencias. Tal vez los jueces no posean la formación profesional necesaria para sacar provecho de la información que requieren las políticas públicas, pero en este punto la aportación deviene contraria: son las políticas públicas y sus diseñadores quienes adoptan $\multimap$, en todo caso, deberían adoptar - los criterios de los jueces para su diseño. La postura opuesta continúa:

Sólo una fracción de todos los diversos intereses afectados por la adopción de una norma jurídica se encuentran representados por las partes que conforman el proceso judicial respectivo, y los casos relativamente escasos que llegan a la etapa de juicio tienen poca probabilidad de ser representativos de la realidad social que la política pública pertinente debe afrontar... (Schuck y Baldwin, 2004).

Tal vez cuantitativamente la pequeña fracción de justiciables que acuden a los tribunales en busca de impartición de justicia no sea representativa de los intereses públicos que son materia de las políticas públicas de una comunidad total cuyo universo poblacional es mucho mayor, ${ }^{19}$ sin embargo, desde un punto de vista cualitativo sí es posible determinar la importancia de los criterios emitidos por los tribunales aunque solamente se trate de una pequeña fracción; los autores finalizan diciendo: ... los tribunales no cuentan con ningún elemento confiable y contundente de retroalimentación para mesurar los efectos reales a los que conducen sus políticas (Schuck, y Baldwin, 2004). En general, en la doctrina se ha sustentado que las políticas públicas y la actividad jurisdiccional no guardan relación alguna y que, incluso, son emitidos por medio de discursos completamente diferentes sustentados por principios que no tienen coincidencia alguna; el argumento para lo anterior es que la característica de técnica y operatividad que poseen las políticas públicas rivaliza con el fundamento normativo de la actividad jurisdiccional (Pérez, 2007). No obstante, se trata de argumentos que no tienen aplicación para los JDLS's, ya que, a pesar de que las políticas públicas y sus diseñadores se retroalimentan de esa actividad jurisdiccional para su configuración, lo importante es la aplicación de los principios y parámetros fundamentales de la democracia, mismos que se verán reflejados en varios aspectos:

\footnotetext{
${ }^{19} \mathrm{Y}$ este es uno de los argumentos que se deben rechazar para el JDLS: no se adopta la democracia como un punto de partida cuantitativo, en donde el mayor número o la prevalencia aritmética tienen el poder de decisión. En este aspecto más bien debe ser considerado como representativo de los intereses de la comunidad.
} 
1. La aplicación o utilización del método hermenéutico más apropiado. Para la resolución del caso el juzgador tiene la facultad de optar por alguno de los métodos de interpretación que se encuentran a su disposición por mandato constitucional y legal y por lo establecido en las convenciones y la jurisprudencia internacionales; se trata de la ejecución de una decisión potestativa dentro de los límites jurídicos mencionados, mismos que representan, en parte, al coto vedado en los JDLS's, y los cuales también contienen los principios de la democracia.

2. El respeto a las etapas del proceso y a los principios procesales. Lo anterior tiene el efecto de garantizar la correcta determinación y resolución del caso (al menos en cuanto a los aspectos procesales), ya que, como quedó establecido antes, se trata de axiomas sostenedores de las formas de actuación del órgano jurisdiccional, de los justiciables y de las propias reglas sustantivas pertinentes. Las etapas también constituyen límites que representan el inicio y la finalización de ciertas actividades dentro del proceso jurisdiccional, en los cuales no se permite la ejecución de actos propios de etapas previas o posteriores, es decir, son cotos vedados.

3. La argumentación y el lenguaje jurídico. Los cuales deben ser adecuados a la comprensión de la población y no específicamente destinados a profesionistas versados en la ciencia del Derecho. El discurso para la resolución de controversias jurídicas se basa en la forma de decirlo, en la construcción de los enunciados que componen la sentencia, los que, dependiendo de su estructuración, pueden atentar contra el juicio democrático, ya que se podría incurrir en una simulación de la verdad procesal o en una representación exagerada o minimizada del contenido en la sentencia y eso perjudicaría seriamente a conceptos como la igualdad o la libertad, y en última instancia a la democracia. En este aspecto el coto vedado está representado por el límite que tiene el juzgador de utilizar el discurso complejo, bajo la regla de que entre menos complejo sea, más democrático será y viceversa.

Se ha considerado que los tribunales son un elemento indispensable para el desarrollo de la democracia en un Estado y también un modelo de moralidad liberal y de ciudadanía democrática; como ejemplo de esto se tienen algunos países en transición democrática que vienen de situaciones de extrema brutalidad, ya sea provocada por el Estado, por el disenso social o por la guerra (Hilbink, 1999). Por ello, los tres aspectos arriba mencionados son una manera de empezar a concebir una conceptualización del JDLS y, por consecuencia, de su adecuado ejercicio en la labor jurisdiccional. Si se considera la importancia de que los 
ciudadanos —y en general la población de un Estado—sean hombres democráticos, con mayor razón se debe exigir que los juzgadores posean esa cualidad y que el producto de su actividad sea consecuente con ello. Los juzgadores democráticos son personas que respetan los axiomas de la democracia y que utilizan la razón y el discernimiento de forma democrática respetando los límites razonables que las categorías democráticas proporcionan, y actúan en congruencia. Un efecto ineludible que es producto de una conducta democrática lo es la deliberación racional que necesariamente respetará normas procesales y fundamentos jurídicos sustantivos, y la consecuencia última de esto es reprimir las conductas irracionales y autoritarias que atentan contra las bases de lo democrático. La transición $\longrightarrow$ y eventual consolidación— de una democracia en un Estado depende, en gran parte, de la existencia previa de un Estado constitucional de Derecho y un elemento indispensable para que esto sea posible es que existan órganos de control de la constitucionalidad y de la legalidad, es decir, órganos jurisdiccionales; por ello, es importante que dichos órganos posean la concepción cabal de lo que un JDLS significa, con la finalidad de que sus decisiones se vean robustecidas por los axiomas de la democracia y de que puedan ser catalogados como democráticos.

\section{CONCLUSIONES}

Primera. Existe la necesidad de conceptualizar la actividad de los órganos jurisdiccionales cuya meta directa no es determinar derechos y obligaciones electorales pero que afectan indirectamente a la praxis democrática en un Estado Constitucional. No se trata de la simple actividad jurisdiccional, cuyo fundamento son las reglas jurídicas, sino también de las reglas esenciales de lo democrático. El criterio que soporte a la actividad jurisdiccional debe ser el democrático, ya que se trata de un sistema de vida que no puede ser ajeno a la actividad de los órganos jurisdiccionales.

Segunda. El hombre democrático es aquel que posee y practica el concepto de democracia; se refleja en su actuar, en su conducta y en sus decisiones como actor social pues cumple las diversas dimensiones que le impone la democracia, es decir, no solamente cumple con sus deberes de ciudadano, sino que además es un ente proactivo que se informa acerca de su medio social, de sus representantes estatales y sus movimientos. También es un receptor y crítico de la información estatal que se le presenta, ejerce sus derechos constitucionales y legales, se asocia para exigir respeto a sus derechos civiles, cumple con sus deberes ciudadanos y ejerce de forma crítica y cabal la libertad de expresión. 
Tercera. La antítesis de los problemas sociales producidos por la tiranía, el totalitarismo, el conformismo, etc., es la democracia, por lo que la justicia adquiere diversas formas, una de ellas es por medio de la ejecución de actos democráticos y sus principios. Es certeza jurídica sobrepuesta a la duda de pertenencia del derecho del acreedor a la justicia.

Cuarta. El JDLS constituye una necesidad básica derivada que no debe intentar satisfacerse con solamente lo que de forma superficial se tiene a la mano respecto de la normatividad en materia de juicios, sino que además se deben aplicar los criterios derivados del neo-constitucionalismo. Dentro del coto vedado se deben resguardar los derechos fundamentales no negociables, lo cual es una condición necesaria de la democracia representativa y fuera de él solamente se encuentran el disenso, la negociación o la tolerancia. El coto vedado es el contenedor de los aspectos procesales que el juzgador no puede negociar ni debe dejar que su aplicación se ponga en riesgo.

Quinta. El argumento para el JDLS tiene su origen en la idea de que el proceso judicial es el aspecto legal de la democracia, pues existe una transmutación ciudadano-Estado a través de la acción judicial que produce una des-incertidumbre democrática. La justificación se encuentra en torno a los principios procesales como manifestaciones democráticas en el proceso judicial.

Sexta. Las políticas públicas y sus diseñadores son quienes deben adoptar los criterios derivados de las sentencias que resuelven casos, para el diseño de las mismas. En la aplicación de los principios y parámetros fundamentales de la democracia se debe respetar la aplicación o utilización del método hermenéutico más apropiado, el respeto a las etapas del proceso y a los principios procesales, así como la argumentación y el lenguaje jurídico.

Séptima. La intención es que el sistema de administración e impartición de justicia en México se apegue a los cánones democráticos y se aproxime cada vez más a un eficaz Estado constitucional y democrático de Derecho, para lo cual la adecuada conceptualización del juicio democrático lato sensu puede aportar elementos de ayuda para que ese desarrollo jurídico y social sea posible y se superen los fallos y errores en el referido sistema de justicia que son contrarios al constitucionalismo y a la esencia democrática de un Estado.

\section{FUENTES DE INFORMACIÓN}

BUSCAGLIA, Edgardo y Dakolias, María, Judicial Reform in Latin America: Economic Efficiency vs. Institutional Inertia, Washington, D. C., George- Town University, 1995.

BUSCAGLIA, Edgardo; DAKOLIAS, María; VAN DIJK, Jan. Global Trends Report on Corruption and Organized Crime, Vienna, UNODC, 2003. 
Deficiencias principales en los sistemas de justicia: propuestas de medidas correctoras, en: El sistema de justicia penal y su reforma. Teoría y práctica, González, Samuel, et. al., Fontamara, México, 2006.

Judicial Corruption in Developing Countries: Its Causes and Economic Consequences, Stanford, Hoover Institution Press, 1999.

Corte Interamericana de Derechos Humanos (CIDH), Caso del Penal Miguel Castro Castro vs. Perú, no. 160, Serie C, 26 de noviembre de 2006.

Caso Comunidad indígena Yakye Axa Vs. Paraguay. Fondo reparaciones y costas, no. 125, Serie C, 17 de junio de 2005. 2009.

Caso de la Masacre de Las Dos Erres vs. Guatemala, no. 211, Serie C, 24 de noviembre de

Caso Gelman vs. Uruguay, no. 221, Serie C, 02, año 2011.

Propuesta de modificación a la Constitución Política de Costa Rica relacionada con la naturalización, solicitada por el gobierno de Costa Rica, no. OC-4/84, enero de 1984.

Diario Oficial, Órgano del Gobierno Constitucional de los Estados Unidos Mexicanos, Constitución Política de los Estados Unidos Mexicanos, tomo CLIX, no. 49, México, lunes 30 de diciembre de 1946.

European Court of Human Rights, Relating to certain aspects of the laws on the use of languages in education in Belgium, no. 1474/62 Application, 23 de julio de 1968.

FLORES García, Fernando, Todavía sobre la carrera judicial, Revista de la Facultad de Derecho, Universidad Nacional Autónoma de México, 1960.

FUENTES, Víctor, México, de los peores en impartición de justicia, periódico Nacional. El Diario.MX, 18 de julio de 2017, en línea: http://diario.mx/Nacional/2012-1203_f0004002/mexico-de-los-peores-en-imparticion-de-justicia/, consultado el 18 de julio de 2017.

GARZÓN Valdés, Ernesto, 2005: El consenso democrático: fundamento y límites del papel de las minorías, Isonomía: revista de teoría y filosofía del derecho, no. 12, año 2005, pp. 7-34.

Algo más acerca del "Coto Vedado", Doxa. Cuadernos de Filosofía del Derecho, no. 6, año 1989, pp. 209-213.

Instituciones suicidas. Estudios de ética política, Universidad Nacional Autónoma de México, México, año 2000.

HILBINK, Lisa, Legalism Against Democracy: The Political Role of the Judiciary in Chile, 19641994, (tesis doctoral), University of California, San Diego, 1999.

MONTESQUIEU, Del espíritu de las leyes, libro XI, capítulo IV, editorial Porrúa, México, 2013.

NúÑEZ Ladevéze, Luis, Masificación y democracia en el modelo de masas, Revista de estudios políticos, Centro de Estudios Constitucionales, España, 1978.

Sociedad de masas versus sociedad del conocimiento, Revista de estudios políticos, Centro de Estudios Constitucionales, España, 1984. 
ORDÓÑEZ Sedeño, Joaquín y De Paz González, Isaac, Estado constitucional y gobernanza: bases para una apertura democrática de las políticas públicas en México, Vniversitas, no. 134, Pontificia Universidad Javeriana, Bogotá, Colombia, 2017, pp. 169-208.

et. al., La observación ciudadana. Orientaciones hacia una meta democratizadora en México, Jurídicas CUC, no. 11, Barranquilla, Colombia, 2015, pp. 135-159.

Legalidad, legitimidad, constitucionalidad y convencionalidad del juicio democrático en México: una causa de disrupción jurídica, Revista de Direito da Cidade, 08, no. 1, año 2016, pp. 245-270.

OVALLE Favela, José, Teoría general del proceso, editorial Harla, México, 1994.

PÉREZ, Luis, Desarrollo, derechos sociales y políticas públicas, en: P. Luis, Rodríguez César, \& Uprymni, Rodrigo (Eds.), Los derechos sociales en serio: hacia un diálogo entre los derechos y las políticas públicas, Bogotá, Instituto para la investigación educativa y el desarrollo pedagógicoIDEP, 2007.

Real Academia Española, Diccionario de la lengua española. Edición del tricentenario, en línea: http://www.rae.es, consultado el 18 de julio de 2017.

RUIZ Mena, Rafael, (coord.), Errores en la procuración y administración de justicia, Instituto Nacional de Ciencia Penales, México, 2010.

SCHUCK, Peter H.; Baldwin, Simeon E., El poder judicial en una democracia, SELA (Seminario en Latinoamérica de Teoría Constitucional y Política), Papers, 2004.

SOBERANES Fernández, José Luis, Algunos problemas de la administración de justicia en México, en: "Jueces para la democracia”, no. 18, España, 1993.

Suprema Corte de Justicia de la Nación, Protocolo de actuación para quienes imparten justicia en asuntos que involucren hechos constitutivos de tortura y malos tratos, México, 8 de enero de 2014,

línea: http://www.sitios.scjn.gob.mx/codhap/sites/default/files/archivos/paginas/Protocolo_tortura_e lectronico_actualizacion.pdf, consultado el 5 de enero de 2016.

Protocolo de actuación para quienes imparten justicia en casos que involucren la orientación sexual o la identidad de género, México, 1 o de agosto de 2014, en línea: http://www.sitios.scjn.gob.mx/codhap/sites/default/files/archivos/paginas/PROTOCOLO_DE_AC TUACION_PARA_QUIENES_IMPARTEN_JUSTICIA_EN_CASOS_QUE_INVOLUCREN_LA_ORIENTACI ON_SEXUAL_O_LA_IDENTIDAD_DE_GENERO_0.pdf, consultado el 6 de enero de 2016.

Protocolo iberoamericano de actuación judicial para mejorar el acceso a la justicia de personas con discapacidad, migrantes, niñas, niños, adolescentes, comunidades y pueblos indígenas, México, enero de 2014, en línea: https://www.scjn.gob.mx/Lists/BannerVerticalV2/Attachments/30/Protocolo\%20lberoamerican o.pdf, consultado el 1 de septiembre de 2016.

Protocolos de actuación para quienes imparten justicia, México, agosto de 2004, en línea: https://www.scjn.gob.mx/libreria/Paginas/protocolos.aspx, consultado el 1 de mayo de 2016.

World Justice Project, Rule of law index 2016, en línea: http://data.worldjusticeproject.org/\#/index/MEX, consultado el 18 de julio de 2017. 
Trabalho enviado em 27 de julho de 2017. Aceito em 16 de outubro de 2017. 